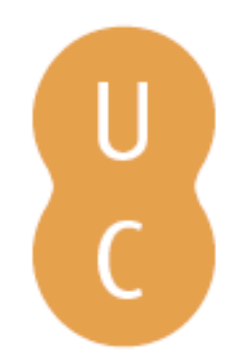

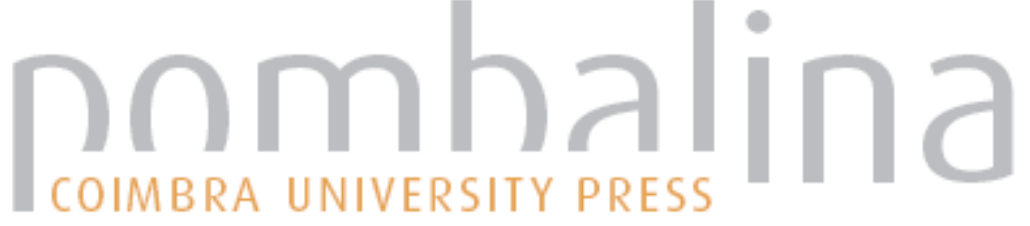

\section{Manuel de Arriaga, António José de Almeida e a Universidade}

Autor(es): $\quad$ Torgal, Luís Reis

Publicado por: Imprensa da Universidade de Coimbra

URL

persistente:

URI:http://hdl.handle.net/10316.2/31189

DOI:

DOI:http://dx.doi.org/10.14195/978-989-26-0437-4_3

Accessed : $\quad$ 26-Apr-2023 13:28:36

A navegação consulta e descarregamento dos títulos inseridos nas Bibliotecas Digitais UC Digitalis, UC Pombalina e UC Impactum, pressupõem a aceitação plena e sem reservas dos Termos e Condições de Uso destas Bibliotecas Digitais, disponíveis em https://digitalis.uc.pt/pt-pt/termos.

Conforme exposto nos referidos Termos e Condições de Uso, o descarregamento de títulos de acesso restrito requer uma licença válida de autorização devendo o utilizador aceder ao(s) documento(s) a partir de um endereço de IP da instituição detentora da supramencionada licença.

Ao utilizador é apenas permitido o descarregamento para uso pessoal, pelo que o emprego do(s) título(s) descarregado(s) para outro fim, designadamente comercial, carece de autorização do respetivo autor ou editor da obra.

Na medida em que todas as obras da UC Digitalis se encontram protegidas pelo Código do Direito de Autor e Direitos Conexos e demais legislação aplicável, toda a cópia, parcial ou total, deste documento, nos casos em que é legalmente admitida, deverá conter ou fazer-se acompanhar por este aviso. 


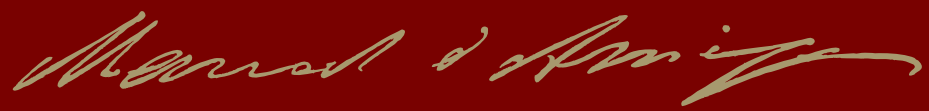

-

-

-

-

-

-

○

-

-

-

-

-

-

-

-

-

-

- 


\section{MANUEL DE ARRIAGA. ANTÓNIO JOSÉ DE ALMEIDA E A UNIVERSIDADE Luís Reis Torgal}


(Página deixada propositadamente em branco) 


\section{Centenário da República, Manuel de Arriaga e as memórias}

Os centenários são actos de memória e até de revisão crítica da própria memória. O Centenário Comemorativo da Primeira República, realizado nestes anos de 2010-2011, foi vasto e multiforme em iniciativas: livros, congressos, conferências, exposições... O centro a que pertenço, o Centro de Estudos Interdisciplinares do Século xx da Universidade de Coimbra (CEIS20), iniciou em Coimbra, de 4 a 6 de Março de 2010, essas comemorações com um colóquio sobre o tema "República, Universidade e Academia" e também colaborou, a título colectivo e individual, na organização de outros colóquios e muitas outras iniciativas, entre elas exposições, que tiveram a participação especial de Alexandre Ramires, nomeadamente as que se realizaram na Biblioteca Geral, no Museu Machado de Castro e no Museu da Ciência, a que se deu o título geral de Ver a República1.

\footnotetext{
1 Ver a República. Catálogo de três exposições realizadas pela Universidade de Coimbra na Biblioteca Geral da Universidade de Coimbra ("Galeria Republicana"), no Museu da Ciência da Universidade de Coimbra ("A Ciência na República") e no Museu Nacional Machado de Castro ("Galeria Ripublicana"). Coimbra, Universidade de Coimbra, 2010.
} 
Todavia, nesta "febre centenarista", passou relativamente despercebida a memória de uma figura fundamental, Manuel de Arriaga, o primeiro Presidente da República eleito e o primeiro reitor da Universidade de Coimbra nomeado pelo Governo Provisório. Felizmente, acabámos por recordá-lo e, assim, a Universidade de Coimbra e a Associação dos Antigos Estudantes do Liceu da Horta pensaram rememorar a figura do jurista e republicano histórico, que se formou em Coimbra e que aqui voltou para cumprir o seu dever de republicano, defender um dos militantes mais fervorosos, o então jovem António José de Almeida, que haveria de o nomear reitor. Curiosamente esse esquecimento já era ve1ho, pois apercebemo-nos também que Arriaga não tem sequer o nome de uma rua em Coimbra, ao contrário de António José de Almeida ou do lente de Matemática José Falcão e de outros cujos nomes ficaram colados a praças e ruas, como Miguel Bombarda, Abílio Roque, Rafael Bordalo Pinheiro, tendo, todavia, alguns vindo a desaparecer da toponímia, por motivos vários.

Porque será que Manuel de Arriaga nunca teve nome de rua ou de praça, em Coimbra, o mesmo não sucedendo noutros lugares? A mesma pergunta se poderia equacionar relativamente a outras personalidades republicanas, como, por exemplo, Afonso Costa. No caso de Arriaga, talvez pelo facto de ter motivado o governo ditatorial de Pimenta de Castro.

A memória é normalmente simples e simplificadora e não encara o passado com a complexidade que supõe. Apenas se limita 
a despertar a atenção para certas figuras por um qualquer motivo significativo ou de circunstância, relegando outras para o plano do esquecimento. O historiador, ao invés, não pode fazer do passado um panegírico ou um tribunal. Assim, mesmo que participe num simples processo de evocação, sem a profundidade da pesquisa, não pode reger-se por essas sensibilidades simplistas e deve recordar, analisando de modo objectivo, todas as figuras históricas, tirando-as do esquecimento, absoluto ou relativo, e relevando a sua importância e significado. Eis, pois, porque aceitei colaborar nesta comemoração, realizada já quase fora de tempo mas sempre a tempo.

Coimbra tem historiadores que se dedicaram mais do que eu ao estudo da República, como Fernando Catroga, Amadeu Carvalho Homem ou Vítor Neto. Por sua vez, existem estudiosos e especialistas de Manuel de Arriaga, como João Bonifácio Serra, Sérgio Campos Matos e Joana Gaspar de Freitas. Todavia, trata-se aqui de evocar Manuel de Arriaga na qualidade de reitor da Universidade e eu tenho, entre outros temas, abordado a história dessa instituição. É essa a razão, bem como o facto de ter escrito a biografia de António José de Almeida, grande amigo de Manuel de Arriaga, por que aceitei gostosamente o convite que me foi formulado pela Doutora Clara Almeida Santos, Vice-Reitora da Universidade de Coimbra, depois de ter sido contactado pelo Professor Henrique Melo Barreiros, dirigente da referida Associação açoriana.

No entanto, devo recordar que, se Manuel Augusto Rodrigues, enquanto director do Arquivo da Universidade de Coimbra e no 
contexto do seu 7. Centenário, em 1990, coordenou um livro sobre $A$ Universidade de Coimbra e seus reitores - na continuação, de resto, de outro trabalho idêntico, de alguns anos atrás, de Francisco Morais (Os reitores da Universidade de Coimbra, 1951) —, onde é abordado, obviamente, o reitor Arriaga, Joaquim Ferreira Gomes publicou, por essa mesma altura, um livro dedicado exactamente ao tema A Universidade de Coimbra durante a Primeira República (1910-1926). A obra de Ferreira Gomes, com o seu carácter narrativo e documentalista, do tipo de "anais", dá-nos conta de todos os elementos necessários para a compreensão do curto mas importante reitorado de Manuel de Arriaga. Mas apenas poderemos recordar o seu trabalho, e mesmo segui-lo de perto, pois, infelizmente, o que foi o fundador da Faculdade de Psicologia e Ciências da Educação da Universidade de Coimbra faleceu em 2002. Não esquecendo outros documentos e outra bibliografia que pude compulsar, será, pois, Ferreira Gomes que serve em grande parte de base a esta evocação.

Manuel de Arriaga e António José de Almeida, militantes republicanos e humanistas

Manuel de Arriaga nasceu na cidade da Horta, nos Açores, em 8 de Julho de 1840. Matriculou-se na Faculdade de Direito da Universidade de Coimbra a 12 de Outubro de 1861, saindo bacharel 
formado em 25 de Maio de 1866. Mas voltou à Universidade para fazer a licenciatura, que concluiu em 24 de Maio de 1875. Naquele ano de 1866, no dia 17 de Julho, agora feriado municipal de Penacova, a que pertence o pequeno povoado de Vale da Vinha (da freguesia de Farinha Podre, hoje São Pedro de Alva), nascia António José de Almeida. Junto estes dois militantes republicanos e humanistas porque a vida, e sobretudo a política, os havia de ligar.

É Manuel de Arriaga quem, em 25 de Junho de 1890, defendeu no tribunal de Coimbra António José de Almeida, então estudante de Medicina, que escrevera, no número-programa do jornal $\mathrm{Ul}$ timatum, o famoso artigo "Bragança, o último", que foi uma das críticas públicas mais violentas contra D. Carlos, tendo como pretexto o Ultimatum inglês de 11 de Janeiro desse ano. Arriaga, nas suas alegações, recordou os acontecimentos antes havidos - o Ultimatum inglês, a perda de liberdades consequente às manifestações que se verificaram, como a dissolução da Associação Académica de Lisboa - , falou do "carácter puramente literário" do texto e dos "interesses sagrados da nação" que pretendia defender, referiu-se ainda ao "carácter puramente doutrinário" do artigo e à carência de um dos elementos essenciais do crime de injúria, "a intenção de causar dano"; utilizou como argumentos atenuantes a "insipiência do réu, em liberdade de imprensa e política", a sua "posição de académico" e o seu "excelente comportamento como estudante e como cidadão". Apesar disso, o juiz Francisco de Assis Caldeira de Queirós - que não aplicou qualquer pena a Afonso 
Costa, que tinha escrito um artigo muito menos contundente no mesmo periódico, sobre a "Federação Académica", mas sim uma multa a Pedro Augusto Cardoso, proprietário da Tipografia Operária, onde o jornal havia sido impresso - aplicou uma pena de três meses de prisão a António José de Almeida. O estudante de Medicina cumpriu a pena na cadeia de Santa Cruz, em Coimbra, e tal foi um dos motivos da sua popularidade, estabelecendo ligações significativas com outros estudantes republicanos, professores (como José Falcão) e operários, tendo vindo posteriormente a publicar muitos artigos no seu jornal mais importante, Resistência.

De resto, ambos estão ligados pela sua militância, e até pelo seu tipo de militância, em prol da República. Manuel de Arriaga foi deputado republicano em várias legislaturas nos anos oitenta e noventa e aí assumiu a defesa das causas mais diversas, o mesmo tendo feito António José de Almeida, sobretudo na legislatura de 1906-1907. Estiveram também juntos em vários comícios nas vésperas da República, em que Manuel de Arriaga presidiu, como velho e consagrado militante, e António José de Almeida foi o principal orador. Assim sucedeu, por exemplo, no comício da rua D. Estefânia, em Lisboa, no dia 12 de Agosto de 1906, ou no dia 27 de Maio de 1907, na avenida D. Amélia. João Franco e a sua ditadura eram então os principais alvos dos republicanos.

Mas Manuel de Arriaga defenderia uma vez mais António José de Almeida na barra do tribunal. Em 18 de Maio de 1907, os jornalistas de O Mundo, França Borges, como director, e Artur Leitão, 
amigo pessoal e colega de profissão de António José de Almeida, como redactor, foram julgados no tribunal colectivo da Boa Hora, por abuso de liberdade de imprensa. Entre as testemunhas estava António José. Fazendo a reportagem da audiência, O Mundo relatou o seu depoimento, o que levou, por sua vez, Almeida à barra do tribunal, dessa vez como réu. Por esse texto jornalístico concluía-se que António José de Almeida defendera Artur Leitão por, indirectamente, chamar "ladrão" a D. Carlos: se o próprio Governo admitia como "ilegais" os "adiantamentos à Casa Real”, facilmente se concluía, genericamente, como fizera o periodista de $O$ Mundo, que, na verdade, "Quem rouba o Estado é ladrão". Nesta altura, Almeida ainda aproveitou para se referir, de forma assumidamente insultuosa, a João Franco e à sua lei sobre a Imprensa, o que levou a uma admoestação por parte do juiz, Miguel Horta e Costa. Com este discurso, entre a expressão clara e a expressão irónica, Almeida atingia assim João Franco e D. Carlos. E, no final, haveria mesmo, em pleno tribunal, de clamar pela Revolução.

António José de Almeida ia, pois, ser julgado, em 17 de Julho de 1907, por este episódio. Em carta-aberta, datada do dia anterior, ao seu defensor, Manuel de Arriaga ${ }^{2}$, que voltava, portanto, a apoiá-lo depois do julgamento de Coimbra, dezassete anos antes,

\footnotetext{
2 Situação clara: carta aberta ao cidadão Manuel d'Arriaga. Lisboa, A. J. de Almeida, 1907. Transcrita na colectânea de escritos e de discursos de António José de Almeida: Quarenta anos de vida literária e política, vol. II, Lisboa, J. Rodrigues e C. ${ }^{a}, 1933$, p. 175 ss..
} 
conta todo o episódio e confirma que o relato de O Mundo correspondia essencialmente à verdade e fora por ele próprio fornecido à redacção do jornal. E o motivo desta confirmação resultava do facto de o ministro da Justiça se ter intrometido no caso, embora o Juiz Horta e Costa quisesse generosamente declinar a responsabilidade de António José de Almeida, afirmando que o que ele dissera no tribunal não correspondia ao que O Mundo escrevera. Foi o próprio António José que procurou o juiz para lhe confirmar a notícia do periódico republicano.

Como se vê, o próprio tribunal passou a funcionar como fórum da oposição republicana. E os jornais atacavam de forma veemente a ditadura e o rei. João Franco reforçou ainda mais a lei de imprensa, permitindo que os governadores civis suspendessem os periódicos prevaricadores. O Mundo acabou por ser suspenso por um mês, por apresentar na sua primeira página do dia 23 de Junho o título "A tirania dos Ladrões - Oprimir para roubar".

Manuel de Arriaga, após ter sido jovem estudante militante nos anos sessenta, fazendo parte da Sociedade do Raio, de ter sido um dos doze subscritores das conferências do Casino Lisbonense em 1871, depois de ter participado no congresso fundador do PRP (1883) e (como se disse) ter sido deputado republicano e também vereador republicano na Câmara de Lisboa, de ter participado no directório do Partido Republicano ainda em 1891 (ano do "31 de Janeiro" do Porto, em cuja revolta, António José de Almeida estava 
para participar em Coimbra, embora com pouco entusiasmo, pois Lisboa havia tentado demover os revolucionários), de ter discursado em sessões de clubes republicanos e de ter estado presente nos momentos de luta do Partido em comícios, conforme referimos, assumiu, contudo, uma postura política mas discreta no final da Monarquia. Assim, afastado do poder de decisão, nem veio a pertencer ao Governo Provisório, nem às Constituintes. Mas foi António José de Almeida que o conduziu à reitoria da Universidade de Coimbra e, depois de ter sido nomeado procurador-geral da República, foi António José quem o propôs para ser candidato a Presidente da República (tinha já 71 anos), sendo eleito, numa campanha conflituosa, por 121 votos em 217. Foi uma presidência dramática e incompleta, com nove governos, culminando com a ditadura do general Pimenta de Castro - que encontrou o apoio do Partido Evolucionista de António José de Almeida e dos "machadistas" (de Machado Santos) - e com o sangrento golpe democrático de 14 de Maio de 1915. Arriaga pediu a exoneração, vindo depois a escrever uma obra justificativa da sua posição política (Na primeira Presidência da República Portuguesa, 1916). Por sua vez, António José de Almeida assumiu, também ele, a derrota do projecto de governo "nacional" de Arriaga - Pimenta de Castro.

António José de Almeida, já depois da morte do seu amigo Manuel de Arriaga, em 5 de Março de 1917 (altura em que era presidente do Conselho de Ministros da "União Sagrada"), veio 
também a ser Presidente da República, tomando posse em 5 de Outubro de 1919 e terminando o mandato em Outubro de 1923. Apesar das múltiplas tragédias da sua presidência, foi o único a cumprir os quatro anos do mandato constitucional.

Pesem embora as diferentes vicissitudes e carreiras de ambos, apesar de pertencerem a gerações distintas e de haver entre eles profundas diferenças temperamentais, algo aproximava este açoriano e este beirão, este jurista e este médico, cujas vidas políticas se foram cruzando por várias vezes. É difícil definir o sentido das suas ideias e muito menos inseri-las num sistema ${ }^{3}$. Têm ambos a mesma difusa influência de diferentes autores em voga entre os republicanos, convergindo nas ideias do cientismo, do laicismo e do idealismo. Poderão os dois, por vezes, em especial na sua juventude, parecer defender ideias próprias de um jacobinismo assanhado, mas ambos se inclinaram, no fundo, para um republicanismo evolucionista, com um marcado espírito de tolerância.

3 No caso de António José de Almeida, ver o nosso livro, com a colaboração de Alexandre Ramires, António José de Almeida e a República, Lisboa, Círculo de Leitores, 2004, principalmente o capítulo 1, intitulado "Um "tribuno popular». A coerência política e as contradições de um político em tempo de mudança". Sobre Manuel de Arriaga, ver a Introdução de Sérgio Campos Matos ao livro Correspondência política de Manuel de Arriaga, Lisboa, Livros Horizonte, 2004, Norberto Cunha, "O positivismo comteano em Manuel de Arriaga (do ponto de vista da dinâmica social)", in O tempo de Manuel de Arriaga, Lisboa, Centro de História da Universidade de Lisboa e Associação de Amigos do Liceu da Horta, 2004, p. 229 ss., e Joana Gaspar de Freitas, Manuel de Arriaga, percurso intelectual e político de um republicano histórico, Lisboa, Caleidoscópio, 2011, p. 29 ss.. 
António José de Almeida fê-lo nos seus discursos parlamentares e de comício e nos seus artigos dos periódicos que fundou, Alma Nacional e República; Manuel de Arriaga também nos discursos parlamentares e nos seus artigos, mas igualmente nas suas obras poéticas e sociais, como no livro Harmonias Sociais (1907) ${ }^{4}$.

António José de Almeida, apesar de negar ter ódio fosse a quem quer que fosse, defendia métodos revolucionários; Arriaga punha em questão, nas vésperas da revolução, esse tipo de métodos. Mas ambos acreditavam numa República em que todos viveriam na mais sã concórdia. Por isso, Ramalho Ortigão, escrevendo, em 1882, o texto para a caricatura de Arriaga, da autoria de Rafael Bordalo Pinheiro, no Álbum das Glórias, falava do seu conceito de sociedade ideal nestes termos irónicos:

Não haverá mais ódios nem mais invejas nem mais intrigas nem mais desesperos nem mais fomes.

Tal é em resumo o plano dele, que provavelmente não se executará nunca, porque tudo isto começa a constar, a polícia sabe-o, e qualquer destes dias metê-lo-á na cadeia como amotinador perverso e monstruoso. E ele perdoará à polícia em belas frases sonoras de uma comiseração infinita, porque ele entende que todo o homem é bom; e foi exactamente

Harmonias Sociais. O problema bumano e a futura organização social (no debute da sua fase definitiva). A Paz dos Povos, Coimbra, França Amado, 1907. 
para poder demonstrar que o crime na humanidade é uma pura invenção dos delegados do ministério público que ele se fez advogado nos auditórios de Lisboa.

Este revolucionário tenebroso, que representa no prisma da política portuguesa o jacobinismo mais sanguíneo, mais rebenta-boi, é um brâmane de cabelos louros e de olhos azuis, modernizado nas lições de Michelet, de Edgar Quinet e de Mickiewicz, mas conservando sempre no fundo da sua alma contemplativa e terna a aversão da guerra e o horror do sangue, que caracterizam as puras e serenas religiões bramânicas. ${ }^{5}$

A história não é o domínio do virtual. No entanto, sem gran-

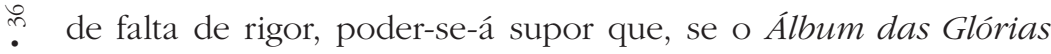
tivesse retratado António José de Almeida anos mais tarde, diria com certeza algo de idêntico. Ele próprio definiu-se assim em momentos retóricos de auto-reflexão, quando se referiu à sua acção política em ligação com a sua profissão de médico ${ }^{6}$.

Parece que ambos se sentiram de tal maneira atraídos pelo sentido revolucionário e ao mesmo tempo de tolerância de Gam-

\footnotetext{
5 Album das Glorias, vol. I, Lisboa, 1880-1902, n. ${ }^{\circ}$ 28, Maio 1882.

6 Ver Discurso na Academia Nacional de Medicina, no Rio de Janeiro, em 22 de Setembro de 1922, in Quarenta anos de vida literária e política, vol. IV, 1934, pp. 263-264.
} 
betta que Arriaga adquiriu e terá lido as suas obras e as terá deixado em testamento a António José de Almeida7.

$\mathrm{Na}$ verdade, talvez Arriaga, apesar de advogado de renome, nem sempre se tenha sentido bem na pele de jurista, o que o levou primeiro a concorrer, sem sucesso, a professor da Academia Politécnica (1867), à cadeira de Economia Política, e, mais tarde, a uma vaga da cadeira de História Universal e Pátria do Curso Superior de Letras (1878), acabando por aceitar um humilde lugar de professor de Inglês nos liceus de Lisboa. Talvez mesmo tivesse pensado que havia na sociedade portuguesa juristas e advogados a mais, dos quais era um deles. Por isso, assim como António José de Almeida em 1895 criticou o espírito de corpo da Faculdade de Medicina, num processo pessoal, e em 1907 veio a criticar a Faculdade de Direito, por altura da greve académica, talvez Arriaga pensasse como ele, tomando posição contra certos vícios do ensino e da Universidade. De resto, a velha instituição de ensino era criticada mesmo pelos seus mestres republicanos, até por aqueles que vieram a tomar uma posição de um republicanismo presidencialista, tendencialmente mais conservador e autoritário, como foi o caso de Sidónio Pais, vice-reitor de Manuel de Arriaga por altura da curta passagem pelo reitorado da Universidade de Coimbra. Vejamos, pois, como se encarava a Universidade nas véspera da revolução republicana.

7 Ver "Dr. Manuel de Arriaga, o seu testamento", in O Século, 6 de Março de 1917, p. 2. 


\section{As críticas à Universidade antes da República}

O excesso de bacharéis era parodiado por Ramalho Ortigão, sob o pseudónimo de João Ribaixo, complementar à caricatura da Universidade da autoria de Rafael Bordalo Pinheiro, intitulada sintomaticamente "Alma Mater. A Mamã dos Bacharéis". Escrevia o autor este texto humorístico:

Apesar porém de todos estes sintomas de senilidade caduca, a Universidade conserva-se fecunda e prolífica, não cessando jamais de criar bacharéis na mesma abundância maravilhosa com que o Mondego cria lampreias, e Santo António dos Olivais cria pencas de manjar branco ${ }^{8}$.

Depois de haverem bebido todo o leite da sabedoria que a Universidade lhes propina, os bacharéis acabam por via de regra estoirando de fome ou indo à sua própria custa aprender outro ofício menos estéril que o de bacharelar.?

\footnotetext{
8 Trata-se de um doce tradicional de Coimbra que estaria ligado a Santo António dos Olivais, onde existia um convento franciscano em que $S$. António ingressara, vindo dos cónegos regrantes de Santa Cruz, mas que - segundo a tradição teria sido feito pelas monjas cistercienses do mosteiro de Celas, um pouco mais abaixo, também nos subúrbios da cidade, mas hoje completamente integrado nela, assim como o referido burgo de Santo António dos Olivais.
}

9 Album das Glorias, vol. I, n. ${ }^{\circ} 34$, Novembro 1882, verso. 
Eusébio Tamagnini, que proferiu a última oração de Sapientia de uma série a que vamos aludir relativa à Universidade ${ }^{10}$, na abertura das aulas do ano lectivo de 1909-1910, e que mais tarde irá fazer no Estado Novo, de que será ministro da Instrução Pública, outra oração em que falou da política de população, que considerou fundamental na política dos Estados, dizia:

[...] o que qualquer pai de família zeloso e fiel cumpridor dos seus deveres exige para os seus filhos é um curso, o diploma final. O resto pouco importa. Ter um filho formado é a aspiração suprema de todo o bom português.

As críticas à Universidade antes da República provinham de todas as áreas da sociedade, quase se tornando uma obsessão. Estudantes de várias gerações - da "geração de 60" (a geração de Antero de Quental, de Arriaga e da "Sociedade do Raio"), mas também de 80-90 (recorde-se o livro de António José de Almeida, Desafronta, de 1895, contra a Faculdade de Medicina ${ }^{11}$ ) e a geração do início do século xx (da greve de 1907 e do ataque sobretudo à Faculdade de Direito) — e professores republicanos cri-

\footnotetext{
10 Ver estas orações no Anuário da Universidade de Coimbra, nos volumes relativos a cada um dos anos lectivos indicados. Também se pode ver em antologias de orações de Sapientia publicadas recentemente, para os casos das Faculdades de Ciências e de Medicina.

11 Desaffronta (Historia d'uma perseguição). 2. ${ }^{a}$ edição. Coimbra, Livraria Moderna de A. d'Oliveira, 1896 (1. edição: 1895).
} 
ticaram a instituição. Os professores fizeram-no (como dissemos) nas orações de Sapientia. São os casos de Bernardino Machado, na abertura solene da Universidade em Outubro de 1904, Sobral Cid, em 1907, Sidónio Pais, em 1908, e Eusébio Tamagnini, a cujo caso especial fizemos referência, em 1909.

Em síntese, as críticas tinham os seguintes objectivos e contornos:

A Universidade não tinha autonomia, nem apoio do Estado, e muito menos das entidades privadas ou do município, como sucedia noutros modelos de Universidade. Assim, citava-se o caso da Universidade de Berlim, concebida no início do século xIX por W. Humboldt, que, apesar do apoio do Imperador, tinha a autonomia científica e as capacidades para o desenvolvimento da investigação. Sobral Cid evoca também o exemplo das universidades inglesas,

? onde as tradições estavam bem enraizadas, ao invés do que (ao contrário do que se dizia) se verificava em Coimbra, e das universidades americanas, que surgiram, com uma forma diferente, pela iniciativa de congregações religiosas, cidadãos ou estados federados. Bernardino Machado, ao falar da Universidade humboldtiana, opinava que na Alemanha se unia a Ciência moderna com a Tradição: "Não existem no mundo mais formosos monumentos para celebrar a aliança da tradição com os mais altos ideais da civilização moderna".

As críticas moviam-se também contra o sistema "eclesiástico", que consideravam dar o tom à Universidade de Coimbra. E, quanto a esta situação, as censuras mais severas vêm, curiosamente, de Sidónio Pais, que descreve as suas características clericais, desde o 
trajo académico aos juramentos religiosos que professores, estudantes e funcionários eram obrigados a proferir. Numa frase bem elucidativa e dirigindo-se ao auditório, sintetiza: "Refiro-me, Senhores, às obrigações de carácter religioso que são impostas aos alunos e professores da Universidade e a esta mistura de serviço de Deus e de serviço de Minerva que me deixa perplexo sobre se foi a Escola que se instalou na Igreja ou se foi a Igreja que invadiu a Escola".

Portanto, desejavam-se alterações a efectuar na Universidade de Coimbra, a única então existente, apesar das escolas criadas durante o liberalismo monárquico irem ocupando cada vez mais o seu próprio lugar no "ensino superior", por vezes com algumas reacções da Universidade, que detinha o monopólio. Mas eram, pois, os próprios lentes, ou alguns deles, a criticar a instituição, lentes republicanos, mas que tinham feito, em certos casos, o seu percurso político na Monarquia, como sucedeu com Bernardino Machado e Sobral Cid, provindos do Partido Regenerador, de que foram parlamentares, tendo o primeiro exercido o cargo de ministro das Obras Públicas (de 22 de Fevereiro a 20 de Dezembro de 1893) num dos governos de Hintze Ribeiro. E se a Faculdade de Direito se defendia das críticas que lhe eram feitas, opinando os seus mestres que ela se tinha modernizado e mesmo transformado numa faculdade simultaneamente jurídica e sociológica ${ }^{12}$,

12 Ver Alberto dos Reis e Marnoco e Sousa, A Faculdade de Direito e o seu ensino, Coimbra, F. França Amado, Editor, 1907. 
a Faculdade de Teologia percebia que já não tinha lugar na Universidade. Assim, no conturbado ano da greve académica, 1907, a Faculdade de Teologia, no seu Conselho, falava da necessidade de reformas, vindo mesmo a pedir, tendo em conta (no seu dizer) que a sua "missão social e religiosa" tinha "atingido o seu termo", a sua transformação numa Faculdade de Letras ${ }^{13}$.

\section{Manuel de Arriaga, reitor da pacificação}

Como acabámos de ver, a Universidade de Coimbra, era a única existente no país, apesar de funcionarem institutos de ensino superior, na tradição da prática da Convenção Francesa (1792-1795), que era contra as universidades, entendidas como corporações de "antigo regime", e defendera a formação de instituições autónomas de ensino. Esta tese convencionista teve alguns seguidores em Portugal e foi-se episódica e difusamente afirmando, em conjunto com a ideia da "Universidade napoleónica" e com as ideias iluministas de tipo pombalino, em certo sentido convergentes. Foi afinal esta amálgama de concepções mal definidas a linha que se sobrepôs na política de ensino superior. Ou seja,

\footnotetext{
13 A.U.C., Actas do Conselho da Faculdade de Teologia. 1901-1912, fls. 55-58v. Sobre esta questão, ver J. Ferreira Gomes, A Universidade de Coimbra durante a Primeira República. 1910-1926, Lisboa, Instituto de Inovação Educacional, 1990, cap. I., pp. 18-20.
} 
havia a ideia de manter uma Universidade única ou "central" (na terminologia napoleónica), com funções de administração escolar, que, depois de se ter efectivado em Coimbra, deu lugar a pouco e pouco a uma política centralizadora na capital, e, a par dela, afirmavam-se as referidas instituições autónomas, algumas com antecedentes desde o tempo pombalino, de que se destacam a Escola Politécnica do Lisboa, a Academia Politécnica do Porto, as Escolas Médico-Cirúrgicas de Lisboa e do Porto e o Curso Superior de Letras. A Universidade de Coimbra, como única, com algumas sobrevivências das prerrogativas corporativas, era assim criticada por várias gerações de estudantes e até de professores. Deste modo, era natural que surgissem revoltas extremistas logo após a implantação da República ${ }^{14}$.

O reitor Alexandre Cabral (de nome completo, Alexandre Ferreira Cabral Pais do Amaral) - formado em Direito, Fidalgo Cavaleiro da Casa Real, membro do Conselho do Rei e Par do Reino, depois de ter sido deputado e ministro do Reino, e que havia sido nomeado no governo de "acalmação" de D. Manuel II, pouco depois do Regicídio, em 10 de Março de 1908 — pede a demissão ao Senado da Universidade, sendo substituído, como reitor interino, pelo lente de Filosofia António Pais Viegas, que havia sido reitor

\footnotetext{
${ }_{14} \mathrm{Na}$ análise da Universidade na República, nomeadamente no tempo do reitorado de Manuel de Arriaga, seguimos basicamente o citado livro de Joaquim Ferreira Gomes, A Universidade de Coimbra durante a Primeira República (1910-1926), p. 43 ss..
} 
por duas vezes (1890-1892 e 1906-1907), uma delas por altura da greve académica.

Os professores insistiram na conveniência de abrir as aulas, o que foi autorizado pelo governo, que marcou essa abertura para 17 de Outubro de 1910. No dia 16, o reitor oficiava ao ministro do Interior, António José de Almeida, que "nenhum juramento foi exigido nem prestado na Universidade, no presente ano lectivo". Mas, em 17 de Outubro, o grupo que se intitulava "Falange Demagógica" invadiu a Universidade, insultou os professores, nomeadamente os da Faculdade de Direito, António José Teixeira de Abreu e José Tavares (que haveriam de se exilar para o Brasil: o segundo seria em 1914 transferido para a Faculdade de Direito de Lisboa e o primeiro foi demitido e reintegrado após o 28 de Maio de 1926),

* destruiu mobiliário, sobretudo as cátedras das salas de aula, e trajes académicos, em especial insígnias da Faculdade de Teologia, e dispararou tiros para os quadros de D. Carlos e de D. Manuel II que se encontram na Sala dos Capelos. O reitor participou o sucedido ao Governador Civil, Francisco Fernandes Costa, e enviou ao ministro do Interior dois telegramas logo nesse dia 17. Na mesma data, a Falange Demagógica, assinando "Os estudantes revolucionários de Coimbra", distribuiu um manifesto, onde realçava a ideia de que era necessário "demolir" a velha Universidade, fechando-a por enquanto e só a abrindo depois de reformada.

Nessa situação de emergência, António José de Almeida, no dia 18, nomeia reitor Manuel de Arriaga, que chega com o minis- 
tro do Interior a Coimbra logo no dia 19, no Sud-Express das 2 horas da tarde, sendo aclamados ambos pela multidão e recebidos pelo Presidente da Câmara, Sidónio Pais. Em Claustro Pleno, nesse mesmo dia 19, o reitor deu posse a Manuel de Arriaga, que prometeu pacificar a Universidade. De tal forma que uma das suas primeiras medidas foi oficiar ao Juiz de Direito, em 22 de Outubro, para que verificasse o delito praticado no dia 17, a fim de remover os destroços provocados, antes de iniciar as aulas de Direito e de Teologia

\section{As primeiras tentativas de reforma da Universidade}

Em decreto de 18 de Outubro de 1910, do Ministério da Justiça, cuja pasta era assumida por Afonso Costa, determinou-se que ficavam proibidos todos os juramentos religiosos e que as pessoas que exercessem qualquer função pública passariam a fazer juramento segundo esta fórmula: "Declaro, pela minha honra, que desempenharei fielmente as funções que me são confiadas". Não era uma legislação referente especificamente à Universidade, mas acabava por lhe ser aplicada com exactidão, dado que era ali que estudantes e professores eram obrigados a proferir juramentos religiosos.

As medidas do ministro do Interior, António José de Almeida, seriam de tal forma significativas e coincidentes com as posições 
do reitor, e do seu vice-reitor, Sidónio Pais (nomeado no dia 23 de Outubro), que Manuel de Arriaga procurou pô-las imediata e escrupulosamente em prática.

Em 23 de Outubro, são promulgados quatro decretos, que pretendiam seguir a orientação que tinha sido anunciada tanto por Arriaga como por Sidónio Pais, na sua oração de Sapientia:

No primeiro desses decretos, são abolidos "para todo o sempre" os juramentos religiosos. No segundo decreto, anulavam-se as matrículas em Teologia, permitindo embora que os alunos do $2 .^{\circ}$ ano ao $5^{\circ}$ ano terminassem o curso. No terceiro, tornava-se as aulas livres e prescrevia-se que os exames só deveriam versar sobre as matérias professadas durante o ano. Finalmente, o quarto decreto considerava facultativo o uso da capa e batina pelos es-

tudantes e mandava passar para a justiça ordinária os casos que eram considerados pelo Regulamento policial académico de 25 de Novembro de 1839, que constituía, com mais algumas práticas, a sobrevivência do tão criticado "foro académico".

O reitor não só providenciou para que estas medidas fossem postas em execução, mas também, em 19 de Dezembro, apresentou aos vários conselhos das faculdades uma proposta de reformas, algumas estruturais e outras meramente de circunstância, apressando-se a informar o ministro do Interior, em 27 de Dezembro, que as propostas, eventualmente transformáveis em decreto do Governo Provisório, haviam sido aprovadas pelos professores presentes. 
Eram dez as medidas que poderiam fazer parte do referido decreto que, no essencial, versavam o seguinte:

1. Seriam suprimidos os ofícios religiosos e o cerimonial que acompanhava a imposição dos graus académicos, considerados doravante apenas de natureza científica.

2. ${ }^{\text {E }}$ Era suprimido o exame de licenciatura, ficando, pois, os graus limitados ao bacharelato (bacharel formado) e ao doutoramento.

3. ${ }^{a}$ Era suprimido o exame de "Conclusões magnas" ou defesa de teses na sala dos Capelos.

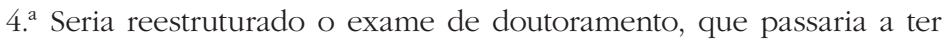
duas provas: a discussão de uma dissertação impressa aprovada pela respectiva faculdade e a discussão da argumentação de três temas, um escolhido pelo candidato e os outros dois pela faculdade.

5. ${ }^{\text {a }}$ Seria obrigatória a aposentação de todos os professores com 70 anos de idade e 30 de serviço.

6. ${ }^{\text {a }}$ Seria fornecido aos lentes de Direito e aos decanos das faculdades o Diário do Governo, para se manterem a par da legislação vigente.

7. ${ }^{a}$ Era autorizado o reitor a fazer uma alteração do selo da Universidade, tirando da Minerva a coroa real e do ceptro a cruz, e passando a ter os seguintes dizeres: "A Ciência leva a toda a parte a Verdade e, com esta, a Liberdade, o Progresso e a Paz dos Povos".

8. ${ }^{\text {a }}$ Seriam provisoriamente aproveitadas algumas salas da Reitoria para melhorar as condições das aulas. 
9. ${ }^{a}$ O reitor seria autorizado a transformar a chamada "Horta" da Universidade, existente atrás do Paço das Escolas, num campo para se efectuarem jogos ao ar livre e se construir um ginásio para exercícios diversos, evitando "a dispersão da Academia por cafés, casas de jogos e outros sítios, onde pouco lucrarão a mocidade e os bons costumes da juventude académica".

10. ${ }^{\text {a }}$ O reitor seria autorizado também a mandar suspender as obras do Teatro Académico, transformando-o no edifício da Associação Académica, onde se instalariam os organismos culturais existentes, bem como gabinetes de estudo.

Tratava-se, como se dizia, de meras propostas do reitor, provavelmente combinadas com o vice-reitor e o ministro do Interior. E,

na verdade, deram origem a três decretos governamentais que só em parte as reflectiam, publicados em 21 de Janeiro de 1911: um que regulava as provas de doutoramento da forma já citada; outro que aposentava os lentes com 70 anos; e um último que extinguia o culto religioso da capela da Universidade, transformando-a em Museu de Arte Sacra.

Outras medidas surgiram durante o reitorado de Manuel de Arriaga, de que se destacam as seguintes: a organização de uma série de conferências públicas, de que a primeira se realizou em 15 de Janeiro de 1911, a formação de uma comissão para estudar a reforma da Universidade e a ideia da formação de um hospital de alienados. Alguns professores foram demitidos, outros pediram a 
exoneração, outros ocuparam as cátedras, como Elísio de Moura, ou ocuparam lugares de relevo, como Ângelo da Fonseca, que se tornou administrador dos Hospitais da Universidade. Também é significativo o facto de se ter pedido a reintegração de Bernardino Machado como lente de Filosofia, de onde saíra voluntariamente em conflito com a faculdade, por altura da greve de 1907, e se ter pedido a amnistia para os estudantes vítimas do "foro académico". E é simbolicamente importante o pedido da Faculdade de Direito para substituir a cadeira de Direito Eclesiástico pela disciplina de Processo Penal, o que foi confirmado por decreto de 14 de Novembro de 1910, chamando-se as novas cadeiras Sociologia Criminal e Direito Penal e Processo Penal.

Quanto às mulheres ${ }^{15}$, pouco ou nada há a dizer, pois as matrículas são anteriores à tomada de posse de Manuel de Arriaga como reitor. Frequentaram a Universidade no ano lectivo de 19101911, oito mulheres, duas no curso de Parteiras, quatro no curso de Farmácia, uma na Faculdade de Filosofia e uma na Faculdade de Direito. Era a primeira mulher que se matriculava nesse curso, Glória Quintanilha, a qual será a primeira advogada portuguesa, quase dez anos depois de Domitila de Carvalho se ter matriculado nas Faculdades de Matemática e Filosofia (1891), preparatórios de Medicina, em que se formaria no ano de 1904.

15 Ver Joaquim Ferreira Gomes, A mulher na Universidade de Coimbra, Coimbra, Livraria Almedina, 1987, p. 25. 
Em 2 de Fevereiro de 1911, Manuel de Arriaga deixava a Universidade. Será, como se disse, primeiro, Procurador-Geral da República, e, depois, o primeiro Presidente da República eleito.

\section{A concluir}

Teria sido lamentável não se evocar, na Universidade de Coimbra, a figura de Manuel de Arriaga. Não se pode dizer que tenha sido um reitor de grande criatividade, nem o poderia ter sido, dado até o seu carácter transitório, mas foi sem dúvida um reitor simbolicamente importante. Foi-o por ter sido o primeiro reitor nomeado na Primeira República, mas também porque esteve ligado às primeiras reformas que o Governo Provisório levou a efeito pela mão do ministro do Interior (ministério magno, com funções em várias áreas, desde os assuntos políticos e de segurança até questões de natureza hospitalar e sanitária, cultural, científica e de educação), António José de Almeida, seu amigo e companheiro de jornada de longa data.

A grande reforma da Instrução Pública virá pouco depois de Manuel de Arriaga ter deixado Coimbra. Primeiro será a reforma da Instrução Primária, pelo decreto com força de lei de 29 de Março de 1911, e depois a reforma da Universidade, pelo decreto com força de lei de 19 de Abril de 1911, de reestruturação do ensino superior. Antes disso já haviam sido criadas as novas Univer- 
sidades de Lisboa e do Porto, em 22 de Março de 1911, a seguir confirmadas pelo citado decreto de 29 de Março.

\section{Bibliografia $^{16}$}

ARRIAGA, Manuel de, Harmonias Sociais. O problema bumano e a futura organização social (no debute da sua fase definitiva). A Paz dos Povos, Coimbra, França Amado, 1907.

ALMEIDA, António José de, Quarenta anos de vida literária e política, 4 volumes, Lisboa, J. Rodrigues e C. ${ }^{a}, 1933-1934$.

CATROGA, Fernando, O republicanismo em Portugal. Da formação ao 5 de Outubro de 1910, Coimbra, Faculdade de Letras, 1991 (2. ${ }^{a}$ edição: Lisboa, Editorial Notícias, 2000).

FREITAS, Joana Gaspar de, Bibliografia de Manuel de Arriaga, Horta, Associação dos Antigos Alunos do Liceu da Horta, 2003.

FREITAS, Joana Gaspar de, Manuel de Arriaga. Percurso intelectual e politico de um republicano bistórico (1840-1917), Lisboa, Caleidoscópio/Comissão Nacional para as Comemorações do Centenário da República, 2011 (tese de mestrado de 2005).

GOMES, Joaquim Ferreira Gomes, A mulher na Universidade de Coimbra, Coimbra, Livraria Almedina, 1987.

GOMES, Joaquim Ferreira Gomes, A Universidade de Coimbra durante a Primeira República (1910-1926), Lisboa, Instituto de Inovação Educacional, 1990.

HOMEM, Amadeu Carvalho, A Propaganda Republicana 1870-1910, Coimbra, Coimbra Editora, 1990.

MATOS, Sérgio Campos (Coord.), O tempo de Manuel de Arriaga. Actas do colóquio organizado pelo Centro de História da Universidade de Lisboa e pela Associação de Amigos do Liceu da Horta. 24 a 26 de Setembro de 2003. Lisboa, Centro de História da Universidade de Lisboa - Associação dos Antigos Alunos do Liceu da Horta, 2004.

16 Apenas se referem aqui os autores e as obras citadas e especialmente consultadas, tendo em atenção que existem várias histórias de Portugal com volumes de síntese dedicados à Primeira República, histórias que abordam especialmente este período e obras monográficas sobre a República, para além de textos gerais e específicos sobre a história da Universidade. 
MATOS, Sérgio Campos, e FREITAS, Joana Gaspar de (Organizadores), Correspondência política de Manuel de Arriaga, Lisboa, Livros Horizonte, 2004.

MATOS, Sérgio Campos; TRAVESSA, Elisa Neves; e FREITAS, Joana Gaspar de (Organizadores), Manuel de Arriaga. Documentos políticos, Lisboa, Livros Horizonte, 2007.

NETO, Vítor, O Estado, a Igreja e a Sociedade em Portugal (1832-1911), Lisboa, Imprensa Nacional - Casa da Moeda, 1998.

PINHEIRO, Rafael Bordalo (desenhos) e João Rialto e João Ribaixo (ORTIGÃO, Ramalho), Album das Glorias, vol. I, Lisboa, 1880-1902.

RAMIRES, Alexandre (Coordenação, investigação, selecção e digitalização de imagens), Ver a República. Textos de Fernando Seabra Santos, Amadeu Carvalho Homem, Luís Reis Torgal, Alexandre Ramires e Paulo Gama Mota. Coimbra, Universidade de Coimbra, Biblioteca Geral da Universidade de Coimbra - Museu da Ciência da Universidade de Coimbra - Museu Nacional Machado de Castro, 2010.

RODRIGUES, Manuel Augusto (dir.), Memoria Professorum Universitatis Conimbrigensis, volume II, 1772-1937. Coimbra, Arquivo da Universidade, 1992.

RODRIGUES, Manuel Augusto, A Universidade de Coimbra e seus Reitores, Coimbra, Arquivo da Universidade, 1990.

SERRA, João B., Manuel de Arriaga. Fotobiografia, Lisboa, Museu da Presidência da República, 2006.

TORGAL, Luís Reis, "A República e a Instrução Pública. O caso do Ensino Superior", in Biblos, nova série, VIII, Coimbra, 2010, pp.127-156.

TORGAL, Luís Reis, "A República e a Universidade", in Maria Cândida Proença (Coordenação), Nos cem anos da Reforma: o quotidiano da Escola Republicana. Organização da Comissão Nacional para as Comemorações da República. Casal de Cambra, Caleidoscópio, 2011, pp. 71-91.

TORGAL, Luís Reis, com a colaboração de RAMIRES, Alexandre, António José de Almeida e a República, Lisboa Círculo de Leitores, 2004 (2. ${ }^{a}$ edição: Lisboa, Temas e Debates, 2005).

TORGAL, Luís Reis, e RAMIRES, Alexandre, António José de Almeida. Fotobiografia. Lisboa, Museu da Presidência da República, 2006. 


\section{Periódicos com notícias sobre Manuel de Arriaga, reitor da U. de Coimbra ${ }^{17}$}

"Uma grande figura da República", Ilustração Portuguesa, Lisboa, n. ${ }^{\circ}$ 245, 31.10.1910 (sobre o novo reitor de Coimbra).

"Em Coimbra", O Século, Lisboa, 30. ${ }^{\circ}$ ano, n. ${ }^{\circ}$ 10.365, 20.10.1910, pp. 1-2 e 5 (Manuel de Arriaga toma posse do cargo de reitor).

"Em Coimbra", O Século, Lisboa, 30. ${ }^{\circ}$ ano, n. ${ }^{\circ}$ 10.366, 21.10.1910, pp. 1-2 (o ambiente revolucionário em Coimbra e a chegada do novo reitor).

"Uma revolução na Universidade", Ilustração Portuguesa, Lisboa, n. ${ }^{\circ}$ 245, 31.10.1910, pp. 552-559 (sobre a nomeação de Manuel de Arriaga como reitor).

José Eugénio Ferreira, "Manuel de Arriaga", O Intransigente. Diário Republicano Radical, Lisboa, ano I, n. ${ }^{\circ}$ 5, 16.11.1910, p. 1. (elogio de Manuel de Arriaga, novo reitor da Universidade de Coimbra).

"Universidade de Coimbra. Mais reclamações do reitor dr. Manuel de Arriaga", O Século, Lisboa, $30 .^{\circ}$ ano, n. ${ }^{\circ} 10.422,17.12 .1910$, p. 5 (reformas que Manuel de Arriaga quer realizar na Universidade).

"Uma série de conferências na Universidade de Coimbra", O Século, Lisboa, 31. ano, n. ${ }^{\circ} 10.449$, 15.1.1911, p. 1.

"Universidade de Coimbra", O Século, Lisboa, 31. ${ }^{\circ}$ ano, n. ${ }^{\circ}$ 10.456, 22.1.1911, p. 5 (decretos publicados enquanto Manuel de Arriaga era reitor).

"Universidade de Coimbra. A despedida do sr. dr. Manuel de Arriaga", O Século, Lisboa, $31 .^{\circ}$ ano, n. ${ }^{\circ} 10.467,3.2 .1911$, p. 1.

"Universidade: Despedida do reitor sr. dr. Manuel de Arriaga - Apresentação do novo reitor sr. dr. Daniel de Matos", Notícias de Coimbra. Folha Independente, Coimbra, ano IV, n. ${ }^{\circ}$ 352, 4.2.1911, p.1.

"A Universidade de Coimbra. Ontem, hoje e amanhã. O que diz o dr. Manuel de Arriaga", República, Lisboa, 22.2.1911 (editorial de António José de Almeida e entrevista com Manuel de Arriaga).

17 Selecção e notas extraídas da obra de Joana Gaspar de Freitas, Bibliografia de Manuel de Arriaga, Horta, Associação dos Antigos Alunos do Liceu da Horta, 2003 . 